\title{
MN20, a D2 Cyclin Found in Brain, Is Implicated in Neural Differentiation
}

\author{
M. Elizabeth Ross and Mathew Risken \\ Laboratory of Molecular Neurobiology and Development, Department of Neurology, University of Minnesota, Minneapolis, \\ Minnesota 55455
}

\begin{abstract}
Cyclins are regulatory proteins that promote the progression of dividing cells through the cell cycle. D-type cyclins are important mediators of the transition from $\mathrm{G} 1$ into $\mathrm{S}$ phase of the cell cycle and are thought to be widely expressed in mitotically active tissues (Matsushime et al., 1991b; Inaba et al., 1992; Xlong et al., 1992). We report the Isolation of a cDNA clone, MN20, which represents a D2 cyclin message form whose expression pattern is highly restricted to brain. MN20 is not ubiquitous, but rather it is expressed only in restricted neuronal precursor populations, for example, in proliferating granule neuroblasts of the cerebellum but not hippocampus. Strikingly, MN20 expression is also found in postmitotic neuronal precursor cells of the embryonic cerebral cortex, but not in the dividing cortical neuroblasts. These observations suggest that the D2 cyclin gene serves regionally specific functions in neuronal differentiation, some of which may be distinct from the promotion of cell cycle progression and which act at the interface between mitosis and the assumption of mature neuronal morphology.
\end{abstract}

[Key words: D2 cyclin, cell cycle, granule neurons, cortical development]

The cell cycle, parceled into phases designated M (mitosis), G1 (first gap), $\mathrm{S}$ (synthesis), and G2 (second gap), is regulated at two major decision points: just prior to the G1-to-S transition (designated "START" in yeast, the "restriction point" in mammalian cells) and the G2-to-M transition. In eukaryotes, the cell cycle is driven by the complex interplay of regulatory cyclin proteins-cyclins A, B, C, D, and E-with protein serine/threonine kinases, designated cdc (cell division cycle gene) 2 , and cdk (cyclin-dependent kinase) 2, 3, 4, and 5 (reviewed in Hunter and Pines, 1991; Xiong and Beach, 1991; Murray, 1992; Sherr, 1993). Specific cyclins, with their cdk partners, have been shown to promote the advancement of different phases of the cell cycle. Thus, $\mathrm{G} 1$ active cyclins $\mathrm{C}, \mathrm{D} 1, \mathrm{D} 2, \mathrm{D} 3$, and $\mathrm{E}$ have been shown to mediate the progression through $G 1 / S$, while $G 2$ cyclins $A$, $\mathrm{B} 1$, and B2 usher the cell through $\mathrm{G} 2 / \mathrm{M}$.

\footnotetext{
Received Feb. 15, 1994; revised Apr. 19, 1994; accepted Apr. 27, 1994.

We thank Drs. John Devereux and Barbara Butler of GCG Inc., Madison, WI, for their help and enthusiastic interest in the analysis of MN20 sequence data. They are also indebted to Dr. Rod Feddersen for use of his Northern filter for MN20 hybridization (Fig. 3) and to Drs. Harry Orr, Joseph Yost, and Karen Hsiao for their careful reading and discussion of the manuscript. This work was supported by a Basil O'Connor Award from the March of Dimes and NIH Grants NS30627 and NS31318 to M.E.R.

Correspondence should be addressed to M. Elizabeth Ross, Department of Neurology, University of Minnesota, 420 Delaware Street SE, Minneapolis, MN 55413.

Copyright (C) 1994 Society for Neuroscience $0270-6474 / 94 / 146384-08 \$ 05.00 / 0$
}

The G1 cyclins have recently drawn much attention for their responsiveness to growth factors (Matsushime et al., 1991a, 1992) as well as for the apparent oncogenic capability of D1 cyclin in parathyroid adenomas (Mokotura et al., 1991), lymphomas (Williams et al., 1993), squamous cell tumors, and breast carcinomas (Bianchi et al., 1993) and the ability of viral insertion in the D2 cyclin gene to produce thymomas (Hanna et al., 1993), thus underscoring the likely relationship of G1 cyclin regulation with cell growth and differentiation. Although a great deal of work has been pursued in continuous cell lines to define the function of $\mathrm{G} 1$ cyclins in the cell cycle, little is known about their role in normal, untransformed cells, particularly during neuronal development and differentiation. Neurons are an exceptional class of cells that both attain mature morphology only after cessation of mitotic activity and persist in the fully differentiated state for the lifetime of the organism. The molecular events that accomplish this seemingly irreversible transition into the postmitotic state and assumption of neuronal morphology are as yet largely unknown.

The early postnatal cerebellum provides an excellent developmental system for the study of genes that act during the transition period between mitosis and assumption of mature neuronal morphology. Having completed their first wave of migration from the rhombic lip, granule neuroblasts of the cerebellum undergo a second burst of proliferation that peaks around postnatal day 8 (P8) (reviewed in Jacobson, 1991). These granule neuron precursors are found in an orderly, laminar array of cells moving sequentially in the first weeks after birth from the mitotically active cells of the external germinal layer (EGL), inward to become postmitotic in the deep zone of the EGL, and from there they migrate to their adult position in the internal granular layer (IGL). In order to examine genes acting within this convenient developmental system, we produced a cDNA library (Kuhar et al,, 1993) using granule cells, purified from P3-P5 cerebella, and screened it with a restriction fragment from the Drosophila neurogenic gene, Notch, which included its cdc10/ SWI6 repeats (Kidd et al., 1989). These motifs were recognized by their similarity to the yeast proteins cdc10 and SWI6, which are transcription factors required for commitment to the cell cycle at START, in late G1 (Nurse and Bissett, 1981; Breeden and Nasmyth, 1987). Among several clones obtained in this screen, analysis of MN20 was pursued because of its strong developmental regulation and apparent tissue specific expression on Northern analysis.

The sequence of the MN20 cDNA corresponds to a message with approximately $5 \mathrm{~kb}$ of $3^{\prime}$ untranslated region (UTR) compared with only $0.9 \mathrm{~kb}$ of open reading frame that encodes the D2 cyclin protein. Data presented here indicate that expression 
of the MN20/D2 cyclin message is highly restricted, both anatomically and temporally, in brain in a manner that cannot be explained solely by the proliferative state of the cells in which it is found. Moreover, the region of the extreme $3^{\prime}$ UTR of MN20 appears to be preferentially expressed in subpopulations of neurons in developing brain, including postmitotic, immature neurons of the fetal cerebral cortex. Observations presented suggest (1) that developing neuroblasts have the ability to select which components of the cell cycle machinery they employ, (2) that posttranscriptional regulation of D2 cyclin protein expression may be used to shape the development of particular brain regions, and (3) that D2 cyclin has additional functions beyond the promotion of the transition from $\mathrm{Gl}$ into $\mathrm{S}$ phase in the cell cycle.

\section{Materials and Methods}

Assignment of gestational dates. For timed pregnancies, dams were examined in the morning, $16 \mathrm{hr}$ after being placed in mating cages and the day in which they developed vaginal plugs was designated E0, while the day of birth was designated P0. Mating pairs were separated on E0 in order to ensure uniformity of timing. In all experiments, the C57Bl/ $6 \mathrm{~J}$ mouse strain was used.

Screening of an early postnatal granule cell library. A cDNA library was constructed from early postnatal mouse cerebellar tissue in which granule neurons are still undergoing mitosis and secondary migration. Cerebellar granule cells from P3-P5 mice were dissociated in trypsin/ DNase and separated from other cell types on Percoll gradients (Hatten, 1985; Gao et al., 1991). Total RNA was prepared by the method of Chomczynski and Sacchi (1987) from $2 \times 10^{8}$ cells and polyadenylated mRNA was selected on oligo(dT)-cellulose (Bethesda Research Labs). cDNA was synthesized (RiboClone system, Promega) from these cells and was directionally cloned into a modified $\lambda$ gt 11 vector (Promega) that contains unique SFiI and NotI sites flanking the original EcoRI cloning site of the phage. First-strand cDNA was made using an oligo(dT)/NotI primer adapter. Following second-strand synthesis, EcoRI adapters were added, the $3^{\prime}$ ends were cut with NotI endonuclease, and cDNA was ligated into the EcoRI $\left(5^{\prime}\right)$, NotI $\left(3^{\prime}\right)$ arms of the phage vector. Approximately $10^{7}$ recombinants with defined orientation were obtained in the primary library.

The amplified library, $2 \times 10^{6}$ recombinant phage, was screened with a $6 \mathrm{~kb}$, HindIII to XhoI, fragment of Drosophila Notch cDNA (gift of Dr. Michael Young, Rockefeller University). Approximately 30,000 colonies per $150 \mathrm{~mm}$ plate were screened using duplicate nitrocellulose filter lifts, hybridized, and washed at low stringency $(2 \times$ SSC, $0.1 \%$ SDS at $55^{\circ} \mathrm{C}$ ). Autoradiograms were developed after $16-48 \mathrm{hr}$ of exposure, and only those colony signals that were present on both of the duplicate filters were picked. In the final rounds of plaque purification, the insert sizes obtained from all signals chosen as positives were identical for a given clone. Moreover, the insert size of each clone agreed with the insert size of the corresponding primary pick, as determined by Southern blotting of PCR products from the plug taken from the primary plate. These features indicate that clones obtained in this manner were not fortuitous selections.

Generation of full-length MN20 cDNA and sequence analysis. The inserts of these phage clones were isolated either by PCR amplification or from phage purified from plate lysates for directional subcloning into pGEM $11 \mathrm{Zf}$ (Promega). Subclones were sequenced by the dideoxy chain termination method (Sanger et al., 1977) with T7 DNA polymerase (Tabor and Richardson, 1987). Comparison indicated that the clones obtained were unique with respect to each other and to searches of nucleotide (hash or ktup values of 6 and 1) and protein (hash or ktup value of 1) databases. Sequence data were entered and compiled using MACVECTOR and ASSEMBLYLIGN software (IBI), while comparisons with existing GenBank, EMBL, and NBRF databases were run using the GCG sequence analysis package (GCG Inc., Madison, WI).

MN20 was selected for further study based on its tissue specificity and temporal regulation during development. Full-length cDNA for the $7 \mathrm{~kb}$ transcript was obtained, first, by rescreening the original library with the initial MN20 isolate, which resulted in two larger clones. This was followed by generation of two successive, specifically primed "mini libraries," using oligonucleotides located $200-300$ bp from the most $5^{\prime}$ end of the available sequence. In this way, eight overlapping MN20

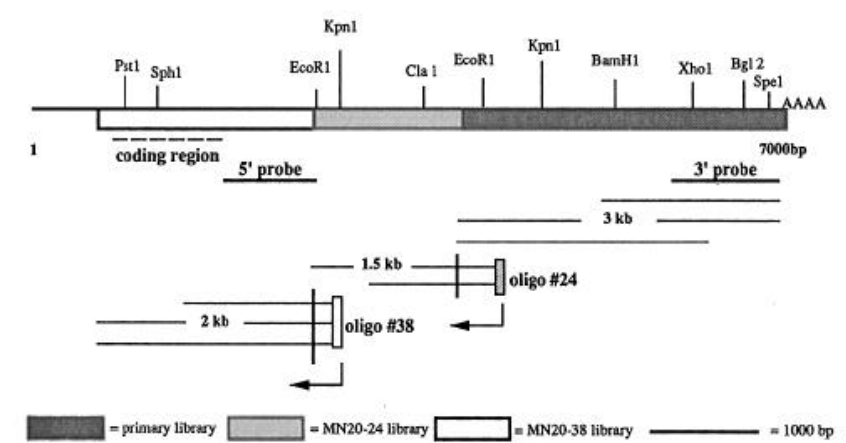

Figure 1. Cloning and sequence analysis of MN20 cDNA: summary of DNA clones. Approximately $6.3 \mathrm{~kb}$ of the expected $7 \mathrm{~kb}$ cDNA has been sequenced. Boxes represent sequences from the eight overlapping clones (solid lines below boxes) obtained from screens of (1) the primary cDNA library (heavily shaded box) and (2) two cDNA "mini libraries" prepared using specific oligonucleotide primers from the available $5^{\prime}$ sequence (oligo \#24, light shaded box, and oligo \#38, open box). Perpendicular lines demarcate the overlap (200-300 bp each) between existing clones and those from newly constructed libraries. The locations of the $5^{\prime}$ and $3^{\prime}$ probes used for Northern analyses and in situ hybridization are shown. The MN20 translated open reading frame was identical with that of the published mouse D2 cyclin (Matsushime et al., 1991b).

cDNAs were obtained. The sequence of these clones was assembled from nested sets of subclones generated by exo III nuclease deletion (Stratagene) in pGEM (Promega) or Bluescript (Stratagene) plasmids.

Northern analysis. Total RNA was prepared by the method of Chomczynski and Sacchi (1987) using either postnatal and adult cerebella or P6 cerebellum, forebrain, lung, heart, kidney, liver, or spleen, as well as the v-myc immortalized granule cell line C17-2 (gift of Dr. Evan Snyder, Harvard Medical School). Northerns were produced using 15$20 \mu \mathrm{g}$ of total RNA from the multiple tissues listed, loaded onto a formaldehyde denaturing gel. Electrophoretically separated RNA was then transferred to nylon membranes and hybridized at $42^{\circ} \mathrm{C}$ for $18 \mathrm{hr}$ with random primed, ${ }^{32} \mathrm{P}$-labeled cDNA probes in hybridization buffer containing $50 \%$ formamide and $10 \%$ dextran sulfate, $1 \mathrm{M} \mathrm{NaCl}$, and $1 \%$ SDS. The final wash stringency was $0.2 \times \mathrm{SSC}, 0.1 \% \mathrm{SDS}$, at $60^{\circ} \mathrm{C}$. Membranes were reprobed with cDNA from the ubiquitously expressed glyceraldehyde- 3 phosphate dehydrogenase (GAPDH) gene. Computerized, camera captured image analysis of Northern autoradiograms was carried out using the IMAGE 1.33 program (public domain, National Institutes of Health).

In situ hybridization. Tissues were fixed in $4 \%$ paraformaldehyde in PBS, pH 7.3. Postnatal day 6 animals were anesthetized with intraperitoneal Nembutal and perfused transcardially by gravity; brains were removed and postfixed in paraformaldehyde for $1-2 \mathrm{hr}$ at $4^{\circ} \mathrm{C}$. Embryonic day 15 animals were sacrificed after anesthetization and drop fixed, either whole or heads only, in paraformaldehyde for $4 \mathrm{hr}$. Fixed tissue was then embedded frozen in Tissue-Tek OCT compound (Miles Inc.), mounted, and sectioned $(10-15 \mu \mathrm{m})$ at $-15^{\circ} \mathrm{C}$ on a microtome and picked up on polylysine- or Vectabond (Vector labs)-coated slides. Tissue sections were acetylated in $0.1 \mathrm{M}$ triethanolamine $\mathrm{HCl}, 0.25 \%$ acetic anhydride, and $150 \mathrm{~mm} \mathrm{NaCl}$, dehydrated through serial alcohols (50$100 \%)$, and stored frozen at $-20^{\circ} \mathrm{C}$ until use. Sense and antisense RNA probes from the far 3' UTR were transcribed in vitro using T7 or SP6 RNA polymerases (Boehringer-Mannheim), respectively, in the presence of $1 \mu \mathrm{M}$ digoxigenin UTP in a $40 \mu \mathrm{l}$ reaction according to the method described for the Genius system (Boehringer-Mannheim). RNA probes were then subjected to partial alkaline hydrolysis to reduce probe size to 200-300 nucleotide fragments. Following treatment in $1 \mu \mathrm{g} / \mathrm{ml}$ proteinase $\mathrm{K}$, slides were again dehydrated and hybridized with probe in buffer containing $50 \%$ formamide, $0.3 \mathrm{M} \mathrm{NaCl}, 0.1 \mathrm{M}$ Tris pH 8,1 mм EDTA, $5 \times$ Denhardt's, $10 \%$ dextran sulfate, and $100 \mu \mathrm{g} / \mathrm{ml}$ yeast tRNA. Slides were incubated for $16-24 \mathrm{hr}$ at $60^{\circ} \mathrm{C}$. The stringency of the final wash was $0.2 \times \mathrm{SSC}$ at $60^{\circ} \mathrm{C}$ for $1 \mathrm{hr}$. Slides were incubated at $4^{\circ} \mathrm{C}$ overnight in alkaline phosphatase-conjugated goat anti-digoxigenin Fab' antibody (Boehringer-Mannheim) at 1:1000 dilution before washing and detection of label with NBT and X-phosphate. 
$\mathbf{A}$

\section{C \\ $\underline{C b} \underline{17-2} \underline{F b} \underline{\mathrm{Sp}} \underline{\mathrm{Li}} \underline{\mathrm{Ki}} \underline{\mathrm{Ht}} \underline{\mathrm{Lu}}$}

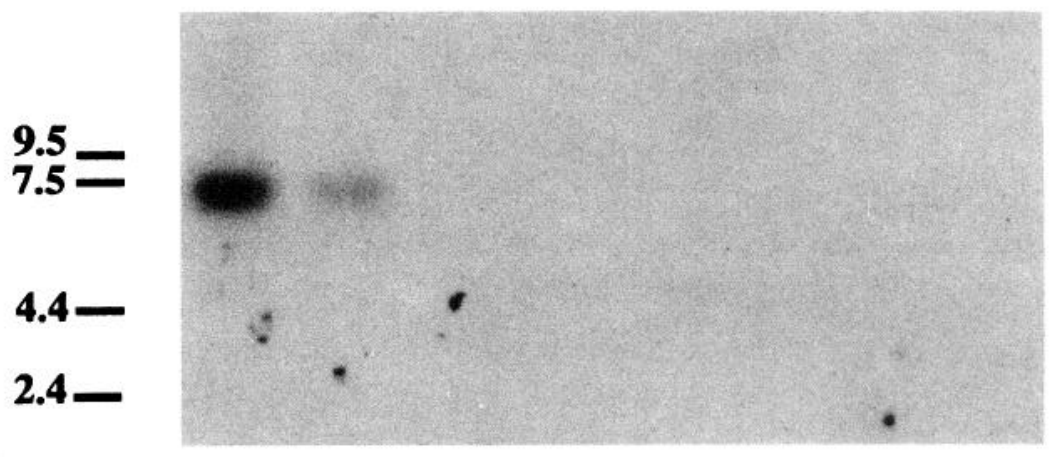

GAPDH

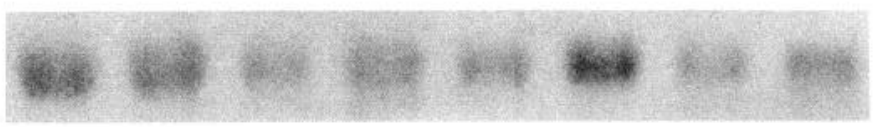

B

Figure 2. Northern analysis of mouse tissues expressing MN20 at postnatal day 6 . Each lane of the formaldehyde gel was loaded with $15 \mu \mathrm{g}$ of total RNA extracted from cerebellum $(\mathrm{Cb})$, the cell line $C 17-2$, forebrain $(F b)$, spleen $(S p)$, liver $(L i)$, kidney $(K i)$, heart $(H t)$, and lung $(L u) . A$, The nylon membrane was hybridized with a fragment from the most distal 3' end of the MN20 cDNA ( $3^{\prime}$ probe designated in Fig. 1). B, A separate filter was prepared using the same total RNA samples (excluding C17-2) and was hybridized with a probe from the 5 ' end of the full-length cDNA (see Fig. 1). Markers on the left indicate band positions (in kb) of the standard ladder. Hybridization with GAPDH probe ( $3 \mathrm{hr}$ exposure) demonstrates relative amounts of RNA per lane.

\section{$\underline{\mathrm{Fb}} \underline{\mathrm{Cb}} \underline{\mathrm{Sp}} \underline{\mathrm{Li}} \underline{\mathrm{Ki}} \underline{\mathrm{Ht}} \underline{\mathrm{Lu}}$}

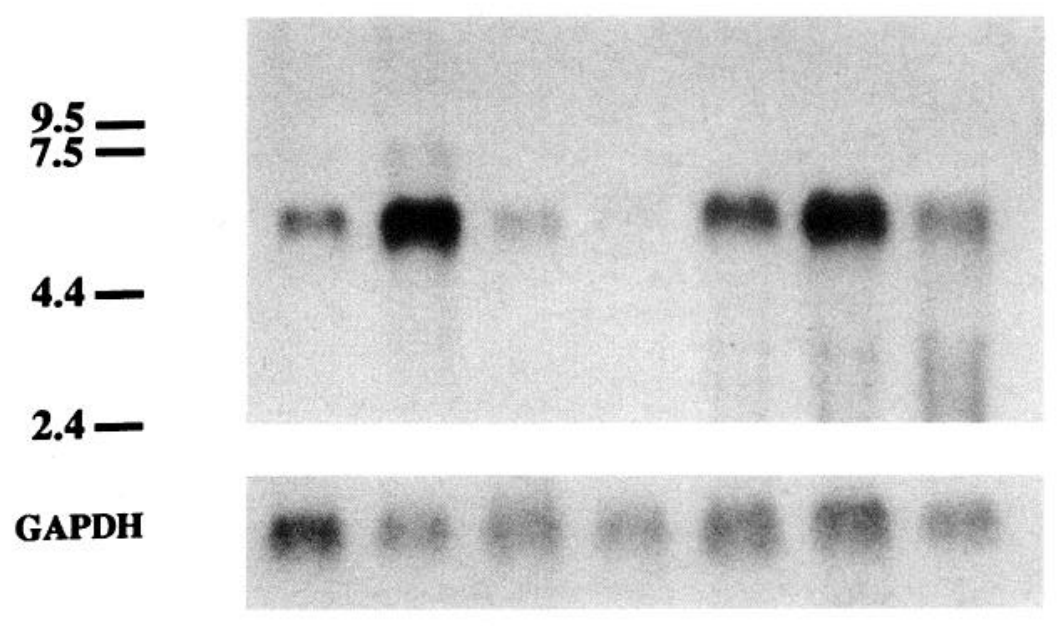

Northern analysis of MN20 tissue and temporal distribution

Northern analysis using a cDNA probe, designated in Figure 1, located at the most $3^{\prime}$ end, reveals a highly restricted expression pattern for the MN20 mRNA (Fig. 2A). At postnatal day 6 (P6), an approximately $7 \mathrm{~kb}$ transcript is detected in the cerebellum and $\mathrm{C} 17-2$, a line of v-myc immortalized cells from the cerebellar EGL that retain the ability to differentiate into granule neurons when engrafted in vivo (Snyder et al., 1992). No transcript was seen in forebrain or tissues outside of the CNS, including liver and spleen, which contain macrophages and lymphoid cells, derivatives of which were previously shown to express a $6 \mathrm{~kb}$ transcript from the D2 cyclin gene (Matsushime et al., 1991a). When a more $5^{\prime}$ probe was used (designated in Fig. 1), located adjacent to the MN20 coding region, two distinct mRNAs were detected: a minor band at approximately $7 \mathrm{~kb}$, seen only in the cerebellar extract, and one of approximately $6 \mathrm{~kb}$, which was seen in all tissues examined (Fig. $2 B$ ) and which presumably corresponds to the message observed by Matsushime et al. (1991a). Thus, distinct subregions of the MN20 cDNA, when 


\section{Postnatal Day}

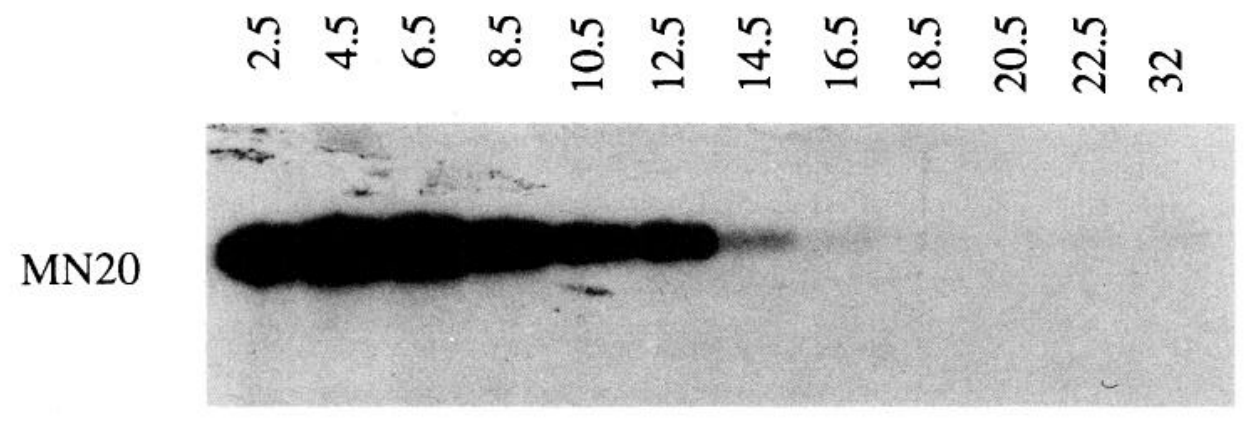

\section{GAPDH}

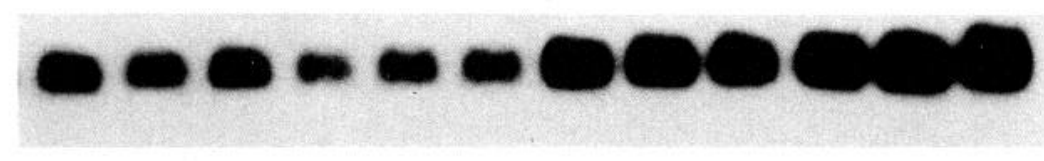

Figure 3. Northern analysis of the temporal expression of $\mathrm{MN} 20$ in the postnatal mouse cerebellum. MN20 expression in cerebellum was compared at ages ranging from postnatal day 2.5 (P2.5) to P32. Total RNA $(20 \mu \mathrm{g})$ was applied to each lane of the denaturing gel. The 3 ' probe (Fig. 1) was used for hybridization of MN20. Hybridization with GAPDH demonstrates relative amounts of RNA per lane. used as probes, are able to distinguish two forms of RNA that differ at their extreme $3^{\prime}$ ends. This observation is supported by the report of Inaba et al. (1992), which demonstrated the presence of several D2 transcripts in different cell lines. Together, these data suggest that there are several alternatively processed forms of D2 cyclin, at least one of which, represented by $\mathrm{MN20}$, is brain specific.

Northern analysis also reveals strong developmental regulation of MN20 in the postnatal cerebellum (Fig. 3). Image densitometric measurements, normalized to measurements of GAPDH hybridization signals, indicate a $>30$-fold decrease in MN20 message levels from P6 to adult in cerebellum. Moreover, expression of MN20 mRNA in the early postnatal cerebellum is sharply downregulated between P14.5 and P16.5. Thus, MN20 mRNA levels in cerebellum follow a time course that parallels the mitotic activity of cerebellar granule neuron precursors in the early postnatal period (Miale and Sidman, 1961).

\section{In situ localization of MN20 expression}

The cellular distribution of MN20 expression was examined by in situ hybridization (Figs. 4, 5) using immunochemical detection of digoxigenin-labeled riboprobe from the far $3^{\prime}$ UTR. In the P6 mouse brain, expression was confined to the superficial lamina of the EGL (Fig. 4), which ${ }^{3} \mathrm{H}$-thymidine studies have demonstrated is composed of proliferating cells (Miale and Sidman, 1961; Fujita, 1967), while cells in the deep zone of the EGL are already postmitotic. Hybridization using the MN20, far 3' UTR probe in P6 sagittal sections did not reveal labeling above background elsewhere in the brain, including the still mitotically active granule neuroblasts of the hippocampal dentate gyrus. This indicates that the expression of MN20 is not simply a marker for all proliferating neural precursors.

At embryonic day 15 (E15), no in situ MN20 label was observed above background in tissues outside of the CNS. As was expected, little if any label was seen in the forming EGL at this earlier age, nor was any label seen in the deeper layers of the cerebellar anlagen. More striking, however, was MN20 expression in a highly restricted cell population outside of the cerebellum, in the developing cerebral cortex (Fig. 5). There, MN20 expression was found in the outermost cortical plate, which at E15 is composed largely of immature postmitotic neurons (reviewed in Jacobson, 1991; O'Leary and Koester, 1993). Im- portantly, no MN20 label was detected above background in the proliferating neuroepithelium of the underlying ventricular zone. Moreover, no MN20 label was seen in the intermediate zone, which is made up principally of proliferating glial precursors (Smart, 1961; Altman, 1966; Mares and Bruckner, 1978; Bayer and Altman, 1991). This indicates that the MN20 form of D2 cyclin mRNA is not simply a marker for the mitotic activity of neural precursors but, rather, is expressed in neurons of the developing cerebral cortex during the transition between mitosis and acquisition of mature neuronal phenotype.

\section{Discussion}

In this study, we have isolated, from early postnatal mouse cerebellum, a cDNA corresponding to a message form of the D2 cyclin gene that differs from the more generally expressed mRNA in its distal 3' UTR. Northern analysis using a probe from the $3^{\prime}$ UTR reveals cerebellar specific expression at postnatal day 6 , while a probe from a more $5^{\prime}$ location in the message reveals a much more general tissue expression pattern. The cellular localization of this MN20/D2 cyclin message form provides a number of insights into the functions of this $\mathrm{Gl}$ cyclin in brain development.

Mounting evidence suggests that cell cycle regulation plays an important role in the differentiation of neurons and establishment of brain cytoarchitecture. For example, determination of the laminar fate of a cerebral cortical neuron appears to be made at the time of the final mitosis of the neuroblast (McConnell and Kaznowski, 1991). In addition, regional differences in rates of cell proliferation contribute to the neuron density and, hence, organization, of striate compared to extrastriate cerebral cortex (Dehay et al., 1993). Furthermore, it has been observed that the duration of the cell cycle in the developing nervous system progressively lengthens during differentiation, for example, in the cranial neural folds and neural tube (Kaufman, 1968; Wilson, 1982). This developmental prolongation of cell cycle time has been attributed to, predominantly, increases in the length of G1. Recent measures of cell cycle duration in cerebral ventricular proliferative epithelium on E14 in the mouse indicate a general cell cycle length of $15 \mathrm{hr}, 9.3 \mathrm{hr}$ of which is spent in G1 (Takahashi et al., 1993), compared with a cycle time of $8 \mathrm{hr}$ in the cranial neural tube at day 10 , with $1.97 \mathrm{hr}$ apportioned to G1 (Kaufman, 1968). Data presented here in- 

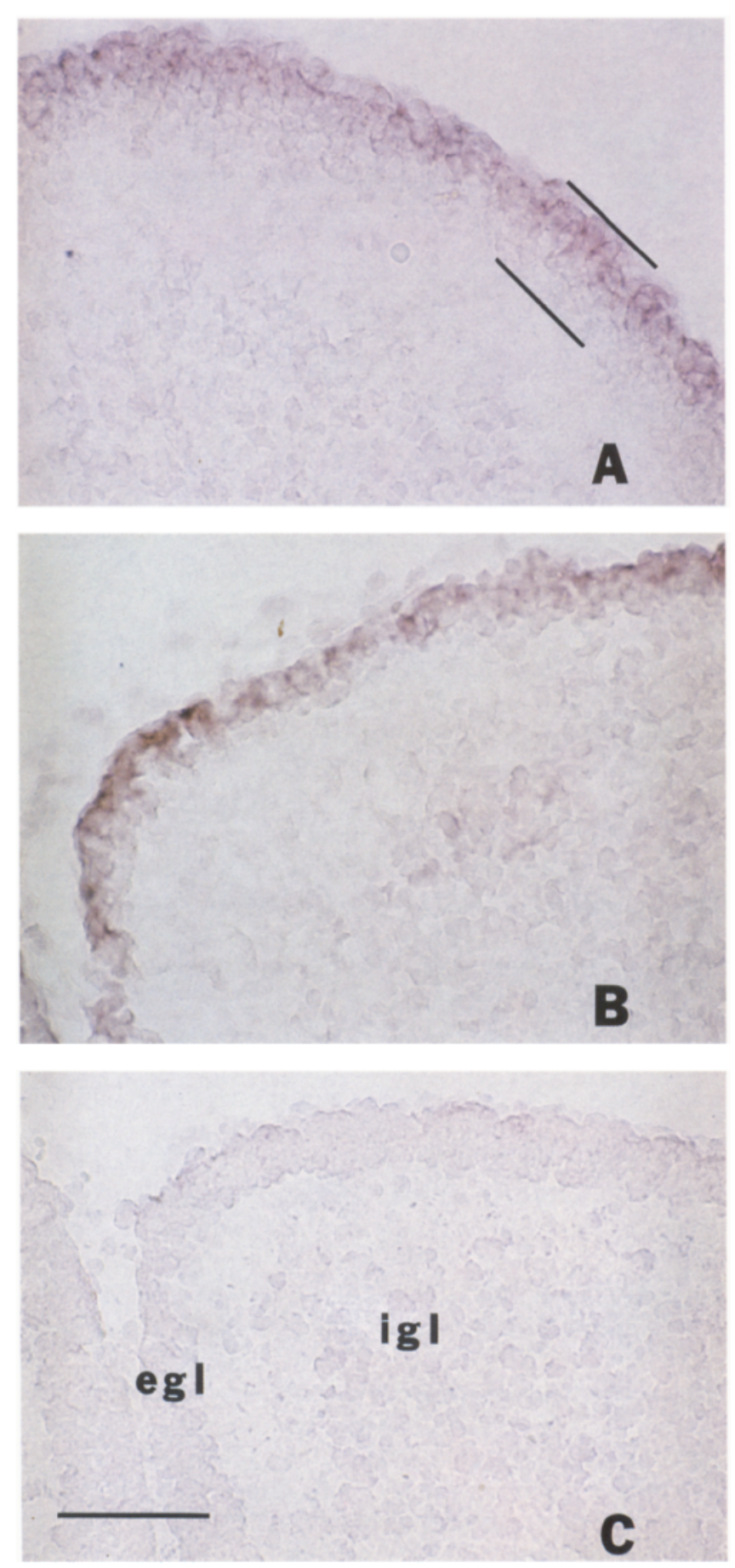

Figure 4. In situ hybridization of $\mathrm{MN} 20$ in sagittal sections of P6 mouse cerebellum. Endogenous MN20 mRNA was hybridized with digoxigenin-labeled probe that was transcribed in vitro from a $1 \mathrm{~kb}$, far 3 ' fragment, subcloned into pGEM $11 \mathrm{zf}$. Hybrids were visualized using alkaline phosphatase-conjugated anti-digoxigenin antibody. $A$ and $B$, MN20-labeled sections. The full thickness of the external germinal layer (EGL) is demarcated by parallel lines in A. Specific labeling of MN20 is confined to the outer, proliferative zone of the EGL in both sections. $C$, Control section. Tissue was hybridized with a sense strand MN20 riboprobe as negative control. egl, external granular layer; igl, internal granular layer. Scale bar, $100 \mu \mathrm{m}$. dicate that specific subpopulations of neuroblasts rely on different components of the cell cycle machinery to proliferate. Thus, MN20/D2 cyclin mRNA is found in the dividing neuroblast populations of the cerebellar EGL at P6, while it is not detected in the dividing granule neurons of the hippocampal dentate gyrus at the same age. Moreover, the presence of the MN20 message form in postmitotic cells of the embryonic cerebral cortex suggests that the D2 cyclin is used in specific neurons at the critical juncture between their exit from the cell cycle and acquisition of mature neuronal phenotype.

\section{MN20/D2 cyclin mRNA localization at P6}

In the P6 mouse brain, MN20 expression detected by the far $3^{\prime}$ UTR probe was found to be confined to the superficial lamina of the EGL, which ${ }^{3} \mathrm{H}$-thymidine studies have demonstrated to be composed of proliferating cells (Miale and Sidman, 1961; Fujita, 1967). This is in agreement with the suggestion by Northern data presented here that MN20 is expressed in cerebellar granule neuroblasts, since MN20 mRNA in postnatal cerebellum is expressed and then downregulated over a period that parallels the emergence of cerebellar granule neurons. Previous studies indicate that the majority of the cells of the EGL give rise to granule neurons (Ramon y Cajal, 1911; Miale and Sidman, 1961; Altman, 1972; Altman and Bayer, 1985). The large number of cells labeling with MN20 are therefore assumed to represent the small mitotically active neuroblasts that begin their initial steps in acquiring neuronal morphology within the deep lamina of the EGL. No label was detected in the deep lamina of the P6 EGL, where these cells become postmitotic, begin initial axon extension, and prepare to descend into the IGL by glia-guided migration (Rakic, 1971; Altman and Bayer, 1985; Edmondson and Hatten, 1987). Moreover, in situ hybridization of the P6 sagittal sections did not reveal labeling above background elsewhere in the brain, including the still mitotically active granule neuroblasts of the hippocampal dentate gyrus. This suggests that the expression of MN20 is not simply a marker for all proliferating neural precursors, and that it may have other region-specific functions in neuronal differentiation.

\section{MN20/D2 cyclin expression in embryonic cerebral cortex}

In order to determine the expression pattern of MN20 at earlier stages, for example, during embryogenesis, in situ hybridization was performed using sagittal sections of the E15 mouse. As expected at this earlier age, little if any of the $3^{\prime}$ MN20 probe was seen to hybridize in cells of the forming EGL, and no label was seen in the deep layers of the E15 cerebellum. More striking, however, was MN20 expression in a highly restricted cell population outside of the cerebellum, in the developing cerebral cortex. The embryonic telencephalon follows a distinctive developmental pattern. Neurons of the mouse cerebral cortex are generated between E11 and E17 (Angevine and Sidman, 1961) in the germinal neuroepithelium of the ventricular zone. When these neuronal precursors become postmitotic, they leave the ventricular zone of the embryonic cerebrum and migrate outward to form five of the six cortical layers (II-VI) in a temporally ordered, inside-out fashion (Berry et al., 1964; Rakic, 1974; Bayer and Altman, 1991; reviewed in O'Leary and Koester, 1993). Thus, neurons born early in cerebral development take a position just below the pial surface to form the cortical plate, whilc later-generated neurons migrate past immature postmitotic neurons in the cortical plate to expand this region and 

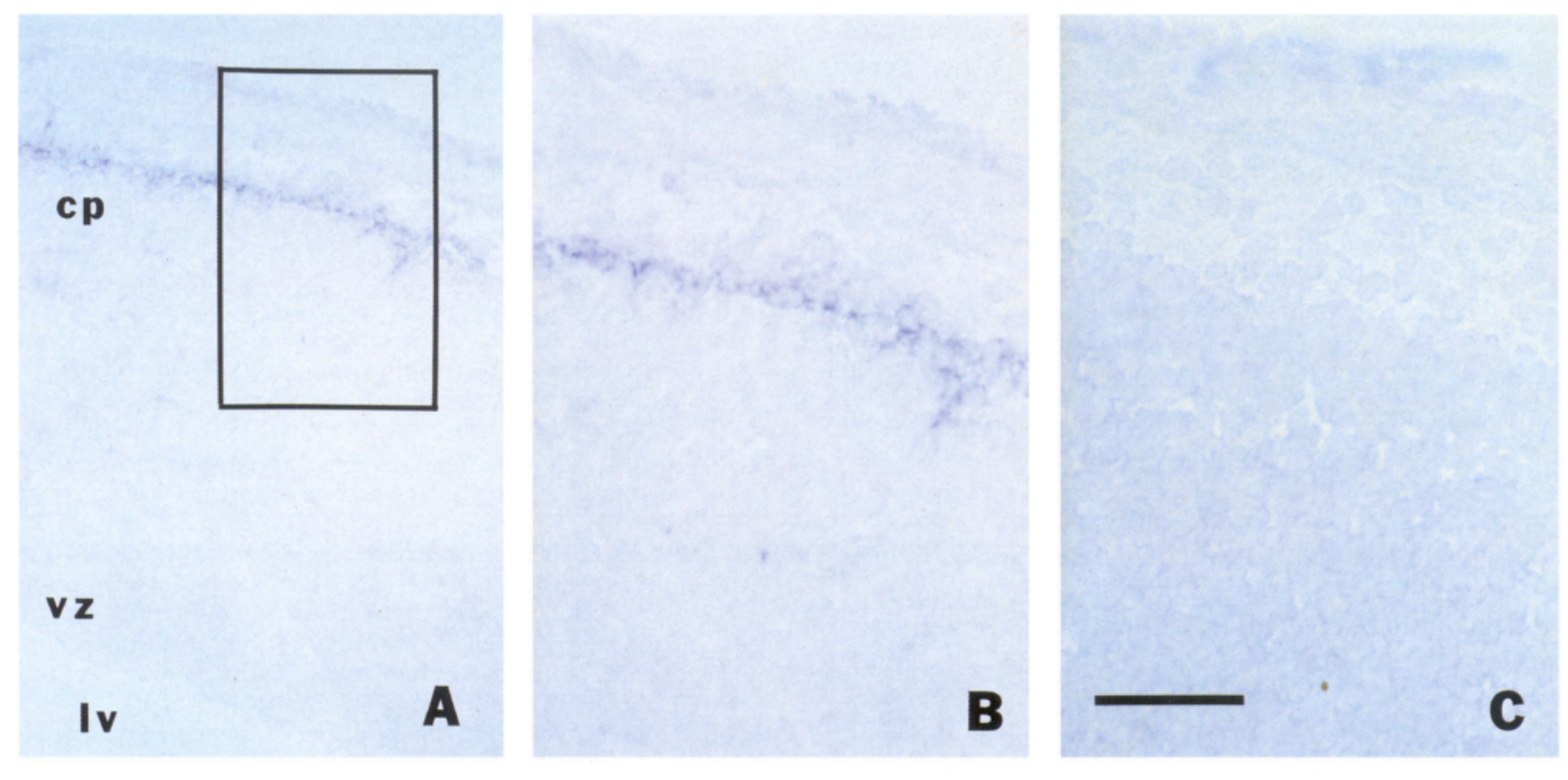

Figure 5. In situ hybridization of MN20 in sagittal sections of E15 mouse cerebral cortex. Sections were labeled with MN20 riboprobe as in Figure 4. $A, \mathrm{MN} 20$ is heavily expressed in a thin layer of cells in the outermost cortical plate ( $c p$ ), which contains mainly postmitotic neurons. No label is seen in the ventricular zone $(v z)$, where the proliferating neuroepithelium is located. $l v$, lateral ventricle. $B$, Higher magnification of boxed area in $A$. $C$, Negative control section hybridized with sense-strand riboprobe. Scale bar, $100 \mu \mathrm{m}$ for $B$ and $C$.

establish progressively more superficial lamina. It is within the cortical plate that these cells begin to assume neuronal morphology by initiating dendritogenesis and synaptogenesis, eventually establishing the morphologically distinct cortical lamina (Marin-Padilla, 1978; Jones, 1984; Thong and Dreher, 1986; Katz, 1991; reviewed in Jacobson, 1991; O'Leary and Koester, 1993).

At E15, MN20 labeling is seen in a thin layer of cells of the most superficial aspect of the cortical plate, extending anteroposteriorly from frontal to occipital cortex. The number and location of cells labeled suggest that these are neuronal precursors that have recently arrived in the developing cortical gray matter (Rakic, 1974; Altman and Bayer, 1990; Bayer and Altman, 1991; O'Leary and Koester, 1993). Moreover, the laminar distribution (one to three cells deep) of the presumed immature neurons suggests that MN20 is transiently expressed in these cells, since many neuroblasts are arriving at the cortical plate during this period (Rakic, 1974; Bayer and Altman, 1991) and MN20 expression, if it were prolonged, should extend through the thickness of the cortical plate. The MN20-labeled cells are not glial precursors, since the few glial cells that arise from the ventricular zone at this age remain scattered in the region of the ventricular zone and in the area below the cortical plate until later in development (Angevine and Sidman, 1961; Bayer and Altman, 1991). Importantly, no MN20 label is detected in the proliferating neuroepithelium of the underlying ventricular zone.

It has been widely accepted from radioautographic (Bayer and Altman, 1991) and fluorescence cytometric (McConnell and Kaznowski, 1991) studies of cortical neurogenesis that neuronal precursors cease to divide just prior to leaving the ventricular/ subventricular zone, well before they reach the cortical plate. Since the cortical plate cells expressing the MN20 message form are not likely to be mitotically active, D2 cyclin in these cortical plate cells must serve another function not directly involved in progression of cells through $\mathrm{Gl} / \mathrm{S}$. Cyclins act as regulatory subunits of several cyclin-dependent kinases (cdk), and these cyclincdk complexes phosphorylate a number of proteins to control the cell cycle. Few of the targets of D2 cyclin-cdk phosphorylation are known (Nigg, 1993; Sherr, 1993). It is possible, therefore, that some cyclin-cdk complexes may, in certain cells, act on proteins that are involved in differentiation and are not directly involved in promoting the cell cycle. This possibility is supported by the recent purification from brain of cdk 5 protein, which in addition to its role in the cell cycle, acts as a neurofilament kinase, expressed in postmitotic neurons (Lew et al., 1992; Tsai et al., 1993).

\section{Possible function of the MN20 message form of D2 cyclin}

The present study indicates that the protein sequence translated from the MN20 coding region is identical to that encoded by D2 cyclin, and that the $7 \mathrm{~kb}$ MN20 mRNA differs from the 6 $\mathrm{kb}$ D2 cyclin transcript in its far 3' UTR. Therefore, the protein encoded by these two mRNAs must have the same biochemical properties. The $3^{\prime}$ end has received much recent attention for the ability of specific $3^{\prime}$ UTR motifs to influence both the stability and the rate of translation of the message (reviewed in Jackson, 1993). This may occur by the degree of polyadenylation, conformational effects on the message, or specific binding of proteins to regions of the $3^{\prime}$ UTR. Therefore, the MN20 mRNA form may have a different longevity or translational activity than the $6 \mathrm{~kb}$ form during the cell cycle. D2 cyclin possesses a rapid turnover rate $(<20 \mathrm{~min})$ and the protein, levels of which peak at G1/S (Ajchenbaum et al., 1993), probably associates transiently with its cdk partners (reviewed in Sherr, 1993). Murray et al. (1989) have shown that a proteolysis-resistant mutant of cyclin-B, a cyclin that acts at G2-M, will persist in $\mathrm{M}$ phase and prevent exit from mitosis both in vitro and in vivo. This observation has prompted others (Sherr, 1993) to speculate that the stable expression of D-type cyclins might 
prevent G1 progression in the cell cycle. One possible model, then, for MN20 function is that this D2 cyclin message persists in an actively translated form longer than other D2 cyclin mRNAs, with resultant prolonged D2 cyclin protein expression, thereby slowing or halting the neuroblast in G1. Such a brake on the cell cycle might permit other differentiation programs to then come into play. This hypothesis will be tested with fusion gene constructs in several expression systems.

The molecular mechanisms that accomplish the irreversible transition of neurons into the postmitotic state and assumption of neuronal morphology are as yet largely unknown. 'The MN20 form of $\mathrm{D} 2$ cyclin reported here is expressed in a highly regional anatomic and temporally restricted distribution within brain that cannot be explained solely by the proliferative state of the cells that express it. The present study provides support for the possibility that certain cell cycle proteins may well be involved at this critical juncture-between proliferation and acquisition of mature morphology - in the differentiation of specific neurons within the CNS.

\section{References}

Ajchenbaum F, Ando K, DeCaprio JA, Griffin JD (1993) Independent regulation of human D-type cyclin gene expression during $\mathrm{Gl}$ phase in primary human $T$ lymphocytes. J Biol Chem 268:4113-4119.

Altman J (1966) Proliferation and migration of undifferentiated precursor cells in the rat during postnatal gliogenesis. Exp Neurol 16: 263-278.

Altman J (1972) Postnatal development of the cerebellar cortex in the rat. The external germinal layer and the transitional molecular layer. J Comp Neurol 145:399-464.

Altman J, Bayer S (1985) Prenatal development of the cerebellar system in the rat. Cytogenesis and histogenesis of the deep nuclei and the cortex of the cerebellum. J Comp Neurol 179:23-48.

Altman J, Bayer S (1990) Horizontal compartmentation in the germinal matrices and intermediate zone of the embryonic rat cerebral cortex. Exp Neurol 107:36-47.

Bayer S, Altman J (1991) Neocortical development. New York: Raven.

Berry M, Rogers AW, Eayrs JT (1964) Pattern of cell migration during cortical histogenesis. Nature 203:591-593.

Bianchi AB, Fischer SM; Robles AI, Rinchik EM, Conti CJ (1993) Overexpression of cyclin D1 in mouse skin carcinogenesis. Oncogene 8:1127-1133.

Breeden L, Nasmyth K (1987) Similarity between cell-cycle genes of budding yeast and fission yeast and the Notch gene of Drosophila. Nature 329:651-654.

Chomczynski P, Sacchi N (1987) Single-step method of RNA isolation by acid guanidinium thiocyanate-phenol chloroform extraction. Anal Biochem 162:156-159.

Dehay C, Giroud P, Berland M, Smart I, Kennedy H (1993) Modulation of the cell cycle contributes to the parcellation of the primate visual cortex. Nature 366:464-466.

Edmondson J, Hatten M (1987) Glial-guided granule neuron migration in vitro: a high-resolution time-lapse video microscopic study. J Neurosci 7:1928-1934.

Fujita S (1967) Quantitative analysis of cell proliferation and differentiation in the cortex of the postnatal mouse cerebellum. J Cell Biol 32:277-287.

Gao WQ, Heintz N, Hatten ME (1991) Cerebellar granule cell neurogenesis is regulated by cell-cell interactions in vitro. Neuron 6:705715.

Hanna Z, Jankowski M, Tremblay P, Jiang X, Milatovich A, Francke $U$, Jolicoeur $P$ (1993) The Vin-1 gene, identified by provirus insertional mutagenesis, is the cyclin D2. Oncogene 8:1661-1666.

Hatten ME (1985) Neuronal regulation of astroglial morphology and proliferation in vitro. J Cell Biol 100:384-396.

Hunter T, Pines J (1991) Cyclins and cancer. Cell 66:1071-1074.

Inaba $T$, Matsushime $H$, Valentine $M$, Roussel MF, Sherr CJ, Look AT (1992) Genomic organization, chromosomal localization, and independent expression of human cyclin D gencs. Genomics 13:565574.
Jackson RJ (1993) Cytoplasmic regulation of mRNA function: the importance of the $3^{\prime}$ untranslated region. Cell 74:9-14.

Jacobson M (1991) Developmental neurobiology, 3d ed. New York: Plenum.

Jones EG (1984) Laminar distributions of cortical efferent cells. In: Cerebral cortex, Vol 1 (Peters A, Jones EG, eds), pp 521-553. New York: Plenum.

Katz LC (1991) Specificity in the development of vertical connections in cat striate cortex. Eur J Neurosci 3:1-9.

Kauffman SL (1968) Lengthening of the gencration cycle during embryonic differentiation of the mouse neural tube. Exp Cell Res 49 $420-424$.

Kidd S, Baylies MK, Gasic GP, Young MW (1989) Structure and distribution of the Notch protein in developing Drosophila. Genes Dev 3:1113-1129.

Kozak M (1986) Point mutations define a sequence flanking the AUG initiator codon that modulates translation by eukaryotic cells. Cell 44:283-290.

Kuhar S, Feng L, Vidan S, Ross M, Hatten M, Heintz N (1993) Changing patterns of gene expression define four stages of cerebellar granule neuron differentiation. Development 117:97-104.

Lew J, Beaudette K, Litwin CM, Wang JH (1992) Purification and characterization of a novel proline-directed protein kinase from bovine brain. J Biol Chem 267:13383-13390.

Mares V, Bruckner G (1978) Postnatal formation of neural cells in the rat oscipital cerebrum: an autoradiographic study of the time and space pattern of cell division. J Comp Neurol 177:519-528.

Marin-Padilla M (1978) Dual origin of the mammalian neocortex and evolution of the cortical plate. Anat Embryol (Berl) 152:109-126.

Matsushime H, Roussel MF, Ashmun RA, Sherr CJ (1991a) Colonystimulating factor 1 regulates novel cyclins during the G1 phase of the cell cycle. Cell 65:701-713

Matsushime H, Roussel MF, Sherr CJ (1991b) Novel mammalian cyclins (CYL genes) expressed during G1. Cold Spring Harbor Symp Quant Biol 56:69-74.

Matsushime H, Ewen ME, Strom DK, Kato JY, Hanks SK, Roussel MF, Sherr CJ (1992) Identification and properties of an atypical catalytic subunit (p34PSK-J3/cdk4) for mammalian D type G1 cyclins. Cell 71:323-334.

McConnell SK, Kaznowski CE (1991) Cell cycle dependence of laminar determination in developing cerebral cortex. Science 254:282285.

Miale I, Sidman R (1961) An autoradiographic analysis of histogenesis in the mouse cerebellum. Exp Neurol 4:227-296.

Motokura T, Bloom T, Kim HG, Juppner H, Ruderman JV, Kronenberg HM, Amold A (1991) A novel cyclin encoded by a bcll-linked candidate oncogene. Nature 350:512-515.

Murray AW (1992) Creative blocks: cell-cycle checkpoints and feedback controls. Nature 359:599-604.

Murray AW, Solomon MJ, Kirschner MW (1989) The role of cyclin synthesis and degradation in the control of maturation promoting factor activity. Nature 339:280-286.

Nigg EA (1993) Targets of cyclin-dependent protein kinases. Curr Opin Cell Biol 5:187-193.

Nurse X, Bissett X (1981) Gene required in G1 for commitment to cell cycle and in $\mathrm{G} 2$ for control of mitosis in fission yeast. Nature 292:558-560.

O'Leary D, Koester S (1993) Development of projection neuron types, axon pathways, and patterned connections of the mammalian cortex. Neuron 10:991-1006.

Rakic P (1971) Neuron-glia relationship during granule cell migration in developing cerebellar cortex. A Golgi and electron microscopic study in Macacus rhesus. J Comp Neurol 141:283-312.

Rakic P (1974) Neurons in rhesus monkey visual cortex: systematic relation between time of origin and eventual disposition. Science 183: 425-427.

Ramon y Cajal S (1911) Histologie du system nerveux de l'home et des vertebres. Paris: Maloine.

Sanger F, Niklen S, Coulson AR (1977) DNA sequencing with chain terminating inhibitors. Proc Natl Acad Sci USA 74:5463-5467.

Sherr CJ (1993) Mammalian G1 cyclins. Cell 73:1059-1065.

Smart I (1961) he subependymal layer of the mouse brain and its cell production as shown by autoradiography after thymidine- $\mathrm{H} 3$ injection. J Comp Neurol 116:325-347.

Snyder E, Deicher D, Walsh C, Arnold-Aldea S, Hartweig E, Cepko C 
(1992) Multipotent neural cell lines can engraft and participate in development of mouse cerebellum. Cell 68:33-51.

Tabor S, Richardson CC (1987) DNA sequence analysis with a modified bacteriophage T7 DNA polymerase. Proc Natl Acad Sci USA $84: 4767-4771$.

Takahashi T, Nowakowski RS, Caviness VS Jr (1993) Cell cycle parameters and patterns of nuclear movement in the neocortical proliferative zone of the fetal mouse. J Neurosci 13:820-833.

Thong IG, Dreher B (1986) The development of the corticotectal pathway in the albino rat. Dev Brain Res 25:227-238.

Tsai L-H, Takahashi T, Caviness VS Jr, Harlow E (1993) Activity and expression pattern of cyclin-dependent kinase 5 in the embryonic mouse nervous system. Development 119:1029-1040.
Williams ME, Swerdlow SH, Rosenberg CL, Amold A (1993) Chromosome 11 translocation breakpoints at the PRAD1/cyclin D1 gene locus in centrocytic lymphoma. Leukemia 7:241-245.

Wilson DB (1982) The cell cycle during closure of the neural folds in the C57BL mouse. Dev Brain Res 2:420-424.

Xiong Y, Beach D (1991) Population explosion in the cyclin family. Curr Biol 1:362-364.

Xiong Y, Menninger J, Beach D, Ward DC (1992) Molecular cloning and chromosomal mapping of CCND genes encoding human D-type cyclins. Genomics 13:575-584. 